\title{
Open Pyelolithotomy in a Pelvic Ectopic Kidney: Case Report and Current Literature Review
}

\author{
Suharjendro Hadisuryo ${ }^{1}$ (D) Ewaldo Hadi $^{1}$ iD, Aria Danurdoro $^{2 *}$ (D) \\ ${ }^{1}$ Department of Urology, West Nusa Tenggara Province General Hospital, Mataram, West Nusa Tenggara, Indonesia; \\ ${ }^{2}$ Department of Surgery, Division of Urology, Faculty of Medicine, Public Health and Nursing, Universitas Gadjah Mada, \\ Dr. Sardjito Hospital, Yogyakarta, Indonesia
}

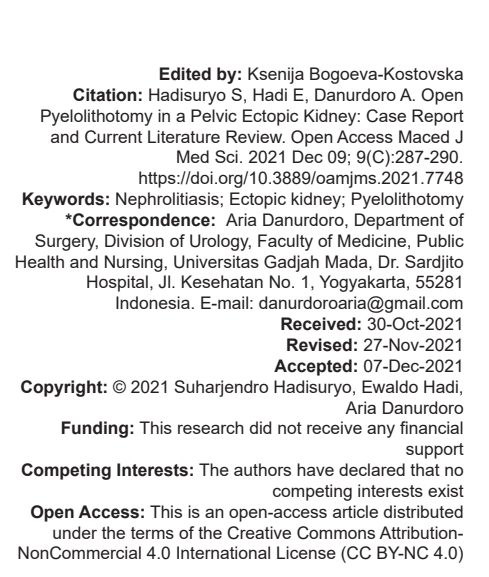

\section{Abstract}

BACKGROUND: Advances in urology have significantly reduced the indications for open surgery to treat staghorn kidney stones. Nevertheless, according to our experience, an open surgery is still the preferred treatment for rare cases of the ectopic pelvic kidney.

CASE REPOPRT: A 49-year-old man complained about pain in the lower umbilical region for five months. The pain drastically changed into a sharp pain 2 months before. The vital sign is normal; on physical examination, the palpation of the suprapubic area elicits pain when pressed, no mass is detected. The abdominal computed tomography without contrast showed a right ectopic kidney located anteriorly of the fifth lumbar to the second sacrum. There was also mild hydronephrosis (grade I) and staghorn stones measuring $4 \mathrm{~cm} \times 2.3 \mathrm{~cm}$. The stone was surgically treated with open pyelolithotomy through a midline infra umbilical incision. The patient was discharged 5 days postoperatively without distinct complications

CONCLUSION: Open surgery can represent a valid alternative in the treatment of kidney stones of very selected cases, including anomalous kidneys, in a setting where resources are limited.

\section{Introduction}

Due to the differential growth of the anterior abdominal wall, the definitive kidney previously originates from the metanephros in the sacrum area will supposedly ascend cranially to its final position in the lumbar region [1]. However, arrested migration will be causing ectopic kidneys [2]. The ectopic kidney located in the pelvic is rare, with an estimated incidence of 1 in 2200-3000 patients [3]. These conditions may remain asymptomatic but may increase the risk of infections, stone formation, high blood pressure, and kidney failure in some patients [4].

In the past few decades, the surgical treatment of kidney stones has undergone tremendous developments. In the past, the most patients required open surgical methods, but today, minimally invasive procedures such as extracorporeal shock wave lithotripsy (ESWL), ureteronephroscopy, and percutaneous nephrolithotomy (PCNL) facilitate open surgery [5]. The subsequent introduction of laparoscopic methods almost eliminated open surgery to treat kidney and ureteral stones. Complex staghorn stones require multiple, simultaneous, or subsequent percutaneous renal access can be facilitated by laparoscopic surgery [6], [7].

In the era of minimally invasive treatment, open surgery is rarely needed. However, it is essential to realize that this approach can represent an effective treatment option for selected patients, especially in the setting of limited resources and anomalous kidneys such as the ectopic pelvic kidney. This article presents a patient diagnosed with ectopic pelvic kidney with right renal pelvic stones who underwent open pyelolithotomy in our hospital.

\section{Case Presentation}

A 49-year-old male complained about pain in the abdomen below the navel. The symptom has been felt in the past 5 months. The patient said that the pain feels such as being squeezed, and in the past 2 months, and the pain has changed into a sharp pain that comes and goes. In addition to the pain, the patient 
also complains about occasional fever. History of bloody urine and urinary stones was denied. The patient denied a history of similar complaints in the family. The patient usually only takes painkillers to relieve pain symptoms that appear, but lately, it has become unbearable even with pain medications.

On physical examination, the patient's general condition is good, the patient's blood pressure is $130 / 90$, pulse rate is $75 / \mathrm{min}$, respiratory rate is $18 / \mathrm{min}$, the temperature is $37.1^{\circ} \mathrm{C}$. General physical examination showed no abnormalities in the patient. During the urological examination, the palpation of the suprapubic area elicits pain when pressed, with no mass being detected. During the examination, there was no tenderness in the right or left flank area. Normal external genitalia, no sign of abnormalities was shown. Laboratory examination of complete blood count, urea and creatinine, hemoglobin was found to be $11.2 \mathrm{~g} / \mathrm{dL}$; leukocytes $9.62 \times 103 / \mu \mathrm{L}$; platelets $214 \times 103 / \mu \mathrm{L}$; urea $46 \mathrm{mg} / \mathrm{dL}$; creatinine $0.4 \mathrm{mg} / \mathrm{dL}$. Computed tomography (CT)-Scan evaluation of the abdomen without contrast (Figure 1) showed an ectopic right kidney in the anterior position in the fifth lumbar to the second sacrum. There was also mild hydronephrosis, dextral renal (grade I), and staghorn stones measuring $4 \mathrm{~cm} \times 2.3 \mathrm{~cm}$.
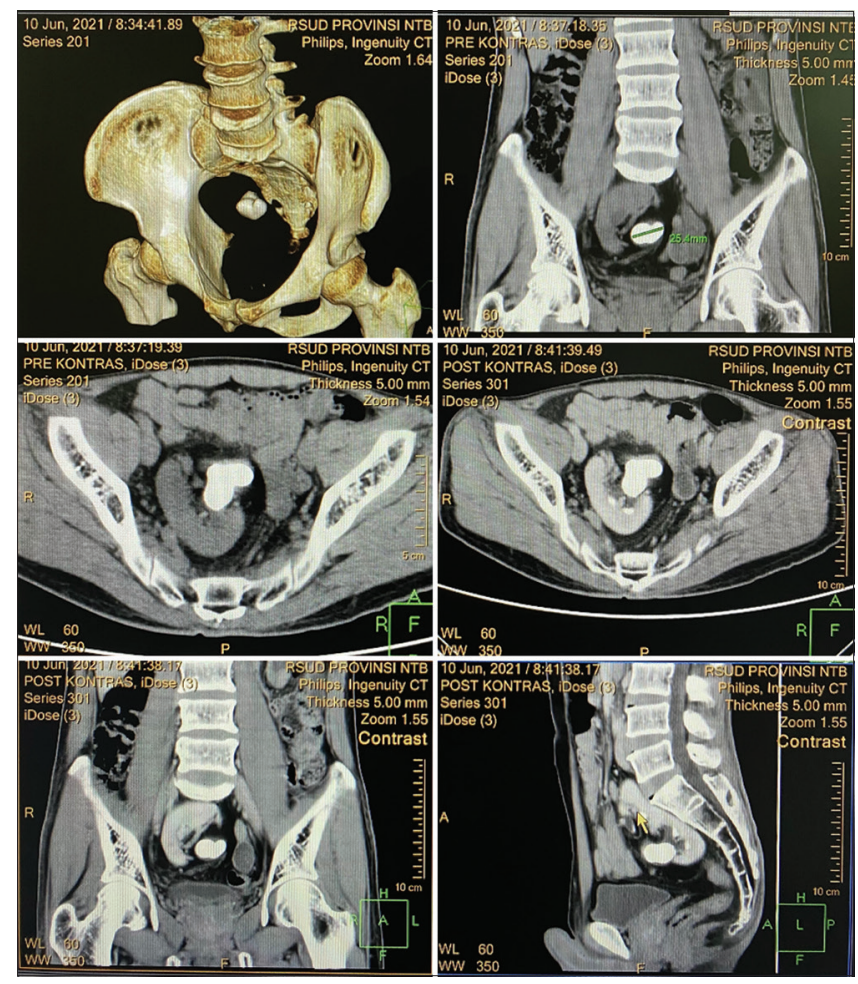

Figure 1: Computed tomography scan of the abdomen shows the appearance stone in right ectopic kidney (pre- and post-contrast)

The pyelolithotomy method is chosen to remove staghorn stones in the right kidney, $4 \mathrm{~cm} \times 2.3 \mathrm{~cm}$ in size (Figure 2). This stone is suspected to be the cause of pain and fever symptoms inpatient. One week after surgery, the patient recovered with no complications encountered.

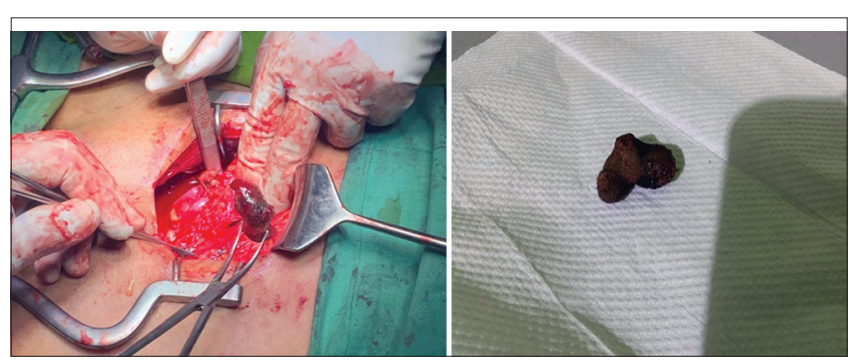

Figure 2: Pyelolithotomy surgery and the appearance of stones in the right kidney after removal

\section{Discussion}

The exact incidence of calculi formation in the pelvic kidney is unknown, but due to anatomical changes and impaired urine flow rate, it is considered higher than the general population [8]. The changes in anatomical structure are indeed significant challenges to surgically treated, especially in larger stones, and the risk of vascular injury has increased relative to the general population [8]. At present, available treatment options for large renal stones $(>2 \mathrm{~cm})$ are ESWL, PCNL, flexible ureterorenoscopy, laparoscopy, and open surgery [5]. ESWL is still a valuable modality in minimally invasive stone surgery for anomalous kidneys. However, the results remain unsatisfactory, especially for larger stones [9]. The utilization of laparoscopically guided transperitoneal PCNL for this condition has been reported before. However, this is technically demanding and could lead to severe complications if performed by someone who is still in the learning curve due to altered orientation of pelvis and calyces, altered renal vasculature, as well as altered relations with intra-abdominal organs, and relative immobility [10], [11], [12], [13], [14]. In some conditions, it also requires extensive laparoscopy equipment, which is not widely available, especially in limited-resources regions. Flexible ureteroscopy or retrograde intrarenal surgery represents reasonable solutions; however, not all centers have this system, especially in secondary hospitals [15]. RIRS also has limitations in removing stones larger than $1.5 \mathrm{~cm}$ and total clearance of residual stones. Compared with percutaneous surgery, the risk of sepsis is also much higher [16].

Although considered historical, open surgery may be the safe alternative with a high stone-free rate to the anomalous kidney with a heavy stone burden, such in our case [17]. This approach is already diminished indications in the present guideline; however, it is still relevant to be implemented in developing countries [18]. It stands to reason, where the resources and expertise is available, the pyelolithotomy can be performed either laparoscopically or robotically to minimize the injury due to anatomical constraints. In this case, we found the renal stone in the pelvic kidney on radiological examination preoperatively, and this was affected our 
decision to perform open pyelolithotomy instead of laparoscopic surgery or PCNL.

Stone configuration and complex stone burden also affected the consideration to perform endoscopic surgery in this case, impacting the stone clearance rate and the need for relook procedure, thus increasing the probability of auxiliary surgery [14]. Although having a high stone-free rate, open surgery also had a higher complication rate than endoscopic modalities [17]. Thus, pre-operative imaging with CT scan is essential to recognize anatomy structure and carefully select the patient.

In our case, we preferred to perform open pyelolithotomy weighing heavy stone burden, the absence of an extrarenal pelvis, the possibility of easy access to stones, and extraction of the stone as a whole without disintegrating it to ensure that it is complete stone-free rates.

\section{Conclusion}

With present advancements in urology armamentarium, open stone surgery is rarely performed. The percutaneous approach is the mainstay for the treatment of large kidney stones. The ectopic pelvic kidney is a rare anatomical variant that warrants careful treatment to minimize the risk of morbidity and mortality. Pre-operative CT scans are essential for identifying ectopic pelvic kidney and surgical plans while aiming for the best stone-free rate. If equipment and expertise are available, CT-guided access is a safe alternative. Another option to use urology expertise is ureteroscopy and lithotripsy in combination with laparoscopic surgery. In the case of limited resources, open renal pelvic lithotripsy is still a safe and effective method of nephrolithiasis when the ectopic pelvic kidney is present.

\section{References}

1. Arrieta MU, Trapote RA, Lizarraga DA. Renal position and fusion anomalies. An Pediatr (Barc). 2011;75(5):329-33. https:// doi.org/10.1016/j.anpedi.2011.05.011

PMid:21724477

2. Alfaseh A, llaiwy A. RCC in cross ectopic kidney: A challenging diagnosis and management. BMJ Case Rep. 2018;2018:1-2. https://doi.org/10.1136/bcr-2018-226879 PMid:30297484

3. Zafar FS, Lingeman JE. Value of laparoscopy in the management of calculi complicating renal malformations. J Endourol. 1996;10(4):379-83. https://doi.org/10.1089/end.1996.10.379 PMid:8872739
4. Yosypiv IV. Congenital anomalies of the kidney and urinary tract: A genetic disorder? Int J Nephrol. 2012;2012:909083. https:// doi.org/10.1155/2012/909083

\section{PMid:22685656}

5. Li JK, Teoh JY, Ng CF. Updates in endourological management of urolithiasis. Int J Urol. 2019;26(2):172-83. https://doi. org/10.1111/iju. 13885

\section{PMid:30575154}

6. Hruza M, Schulze M, Teber D, Gözen AS, Rassweiler JJ Laparoscopic techniques for removal of renal and ureteral calculi. J Endourol. 2009;23(10):1713-8. https://doi.org/10.1089/ end.2009.1539

PMid: 19785553

7. Simforoosh N, Aminsharifi A. Laparoscopic management in stone disease. Curr Opin Urol. 2013;23(2):169-74. https://doi. org/10.1097/MOU.0b013e32835d307f

PMid:23357934

8. Cinman NM, Okeke Z, Smith AD. Pelvic kidney: Associated diseases and treatment. J Endourol. 2007;21(8):836-42. https:// doi.org/10.1089/end.2007.9945

PMid:17867938

9. Satav V, Sabale V, Pramanik P, Kanklia SP, Mhaske S. Percutaneous nephrolithotomy of horseshoe kidney: Our institutional experience. Urol Ann. 2018;10(3):258-62. https:// doi.org/10.4103/ua.ua_152_17

PMid:30089983

10. Mosavi-Bahar SH, Amirzargar MA, Rahnavardi M, Moghaddam $\mathrm{SM}$, Babbolhavaeji $\mathrm{H}$, Amirhasani S. Percutaneous nephrolithotomy in patients with kidney malformations. J Endourol. 2007;21(5):520-4. https://doi.org/10.1089/ end.2006.0349

PMid:17523906

11. Gupta NP, Mishra S, Seth A, Anand A. Percutaneous nephrolithotomy in abnormal kidneys: Single-center experience. Urology. 2009;73(4):710-4; discussion 714-5. https://doi. org/10.1016/j.urology.2008.10.070

PMid:19193423

12. Netto NJ, Lemos GC, Fiuza JL. Colon perforation following percutaneous nephrolithotomy. Urology. 1988;32(3):223-4. https://doi.org/10.1016/0090-4295(88)90388-3

PMid:3413914

13. Goswami AK, Shrivastava $P$, Mukherjee A, Sharma SK. Management of colonic perforation during percutaneous nephrolithotomy in horseshoe kidney. J Endourol. 2001;15(10):989-91. https://doi org/10.1089/089277901317203065

PMid:11789981

14. Prakash G, Sinha RJ, Jhanwar A, Bansal A, Singh V. Outcome of percutaneous nephrolithotomy in anomalous kidney: Is it different? Urol Ann. 2017;9(1):23-6. https://doi. org/10.4103/0974-7796.198836

PMid:28216924

15. di Franco CA, Burrello M, Guzzardi F, Intagliata E, Oxenius I Galvagno L, et al. Management of a kidney stone in ectopic pelvic kidney with extracorporeal shockwave litothripsy: Description of a case and revision of literature. Arch Ital Urol Androl. 2020;92(2):109-11. https://doi.org/10.4081/aiua.2020.2.109 PMid:32597111

16. Zhang W, Zhou T, Wu T, Gao X, Peng Y, Xu C, et al. Retrograde intrarenal surgery versus percutaneous nephrolithotomy versus extracorporeal shockwave lithotripsy for treatment of lower pole renal stones: A meta-analysis and systematic review. J Endourol. 2015;29(7):745-59. https://doi.org/10.1089/end.2014.0799 PMid:25531986 
17. Patandung R, Prapiska FF, Kadar DD. Open pyelolithotomy in an ectopic kidney: A case report. Urol Case Rep. 2021;35:101528. https://doi.org/10.1016/j.eucr.2020.101528

PMid:33364173
18. El-Husseiny $\mathrm{T}$, Buchholz $\mathrm{N}$. The role of open stone surgery. Arab J Urol. 2012;10(3):284-8. https://doi.org/10.1016/j. aju.2012.03.004

PMid:26558038 